\title{
Trophic ontogenetic shifts of the dragonfly Rhionaeschna variegata: the role of larvae as predators and prey in Andean wetland communities
}

\author{
Fabián Gastón Jara* \\ Laboratorio de Fotobiología, Instituto de Investigaciones en Biodiversidad y Medioambiente (INIBIOM-CONICET), Quintral 1250, \\ San Carlos de Bariloche 8400, Río Negro, Argentina
}

Received 18 October 2013; Accepted 16 March 2014

\begin{abstract}
Body size strongly influences the type and strength of species interactions. Animals with complex life cycles, such as dragonflies, usually go through different stages that include a variation in body size and may involve shifts in their trophic position in the food web. This investigation analyzes the position of the dragonfly Rhionaeschna variegata, in the food web according to its body size, in Andean wetland communities of Northwestern Patagonia (Argentina). The phenology of $R$. variegata larvae and their potential intraguild predators were studied in wetlands with different hydroperiods. Under controlled experimental conditions, feeding trials were performed to assess the effect of $R$. variegata on the survivorship of different types of prey. The effects of cannibalism and intraguild predation (IGP) on the survivorship of the small larvae of $R$. variegata were investigated with and without alternative prey as well as different sympatric predators. The phenology of $R$. variegata and intraguild predators differed among wetlands. The feeding trials showed that $R$. variegata has a significant effect on the survivorship of invertebrate and vertebrate prey. Cannibalism increased with body size in odonate larvae. The survivorship of small- and medium-sized larvae was mainly affected by the presence of larger predators such as belosmatids. The field and experimental data show that the effect of IGP and cannibalism is affected by the cohort dynamics of $R$. variegata. Body size in $R$. variegata determines the strength of its interaction with other components of the community.
\end{abstract}

Key words: Intraguild predation / cannibalism / alternative prey / body size / phenology

\section{Introduction}

Relative body size, often identified as a major determinant of the food web structure, is a primary factor influencing the direction of interactions among species (Warren and Lawton, 1987; Cohen et al., 1993; Memmott et al., 2000; Urban, 2007). Size-related constraints on feeding can influence the resource partitioning and trophic status within food webs. Because the trophic status generally increases with body size, species may change their status during their development. This is common in animals with complex life cycles, such as aquatic insects and amphibians that are common components of temporary freshwater environments. During their life cycle, wetland species may experience predation at different stages (eggs, larvae and juveniles) and also may change their diet and feeding habitat (Wilbur, 1984; Vonesh, 2003). In some cases, both cannibalism by large

\footnotetext{
*Corresponding author: fjara77@hotmail.com
}

conspecifics and predation by other species of the same guild (intraguild predation (IGP)) have been frequently observed. A guild is defined as a group of species that exploit the same class of environmental resources in a similar way (Simberloff and Dayan, 1991). For example, in this study, aquatic insect predators in Andean wetland communities form the same guild because they feed on the same prey resources: mosquito larvae, zooplankters and tadpoles.

IGP is a common biotic interaction that combines predation and competition, because both species are usually included in the same trophic guild, sharing prey resources and preying upon one another. Many researchers have highlighted the importance of IGP in natural communities (e.g., Arim and Marquet, 2004). Cannibalism, a particular case of IGP that occurs when intraspecific competitors eat each other, is frequently reported within populations of species that interact as intraguild predators (Wissinger et al., 1996). Both interactions are common in guilds of omnivorous predators 
(sensu, Pimm, 1978) in which larger species or conspecifics prey on smaller species or smaller conspecifics. IGP is widespread in freshwater ecosystems and has been observed among odonates, beetle larvae, water bugs, fish and amphibians (Heyer et al., 1975; Johansson and Crowley, 2008). Relative body size and degree of trophic specialization are two important factors influencing the frequency and direction of IGP (Ilmonen and Suhonen, 2006). Cannibalism has been considered as an important source of larval mortality in odonates (Benke and Benke, 1975; Merrill and Johnson, 1984; van Buskirk, 1989, 1992; Wissinger, 1989). Most studies on IGP and cannibalism oversimplify the interaction within the food web by excluding the effect of alternative prey that may actually modify the outcome of the interaction (Holt and Huxel, 2007).

The Andean forest wetlands in Northwestern Patagonia (Argentina) are particularly interesting due to their diversity and endemism (Perotti et al., 2005). The food webs of autumnal and vernal wetlands may be complex depending on the hydroperiod (Jara et al., 2013). In these fishless communities, top predation is exerted by insects, such as odonates, aquatic beetles and water bugs. Most of these predatory insects feed on the same food resources: zooplankton, herbivorous and omnivorous macroinvertebrates and anuran tadpoles (Jara et al., 2012, 2013).

In predatory insects such as dragonflies, cannibalism and IGP have been observed in several investigations (Hasse, 1978; van Buskirk, 1989, 1992; Johansson, 1991a, 1991b, 1993; Wissinger, 1992; Wissinger and McGrady, 1993; Suutari et al., 2004; Ilmonen and Suhonen, 2006; Bo et al., 2011). Dragonflies may be bivoltine, multivoltine or partivoltine, thereby experiencing usually the cooccurrence of different developmental stages. In this scenario, cannibalism generally occurs among larvae of dissimilar size or belonging to different cohorts (Benke, 1978; Polis et al., 1989; Corbet, 1999). The larvae feeding on a wide range of prey sizes, mainly on benthic organisms, may also feed on pelagic organisms influencing their survivorship (Burks et al., 2001). In dragonflies, predation rate and prey access increase with body size; therefore, larger larvae can even consume fish and tadpoles (Jara, 2008).

In Patagonia, five species of Rhionaeschna (Odonata: Anisoptera) dragonflies have been recorded so far (Muzón and von Ellenrieder, 1999; von Ellenrieder, 2001). Rhionaeschna variegata (Fabricius, 1775) (Aeshnidae) is the southernmost dragonfly species, being the most common odonate in Patagonia (Muzón, 1995, 2009). This species is a common weed-dweller which inhabits a wide range of wetlands, including temporary ponds, shallow lakes and backwaters of rivers and streams (Muzón, 1995, 1997; author's personal observation). The larval development of $R$. variegata may be univoltine or bivoltine, and may occur through 10-12 instars (Muzón J., personal communication). The population of $R$. variegata seems to have no seasonal synchronization. In some cases, the adults reproduce in early autumn and then larvae of different stages and sizes can be found cooccurring (Muzón, 1995; author's personal observation). $R$. variegata larvae prey on different species of zooplankters, mosquito larvae and tadpoles (Jara and Perotti, 2006, 2009, 2010). The natural overlap of larval stages and sizes observed normally in temporal and permanent wetlands suggest that this system is amenable to study the role of $R$. variegata larvae as predators and prey. To investigate this subject, the phenology of odonate larvae and the cooccurrence of sympatric predators were studied in three wetlands with different hydroperiods. Under experimental conditions, the effect of $R$. variegata larvae on common prey communities was analyzed in relation with its body size. To study cannibalism and IGP, two experiments were carried out. The first experiment aimed to evaluate the effect of Rhionaeschna size as a variable influencing its potential for cannibalism, in the presence or absence of alternative prey; whereas the second experiment is aimed to study the incidence of IGP on the co-occurrence of Rhionaeschna and other predatory insects varying alternative prey availability.

\section{Methods}

\section{Field study}

Three wetlands, Laguna Fantasma and Llao-Llao marsh (both eutrophic and temporary), and a large backwater area in the Gutiérrez stream (oligotrophic and permanent) were selected to study the phenology of $R$. variegata and sympatric predators. These wetlands are located in the western suburbs of San Carlos de Bariloche city (Patagonia, Argentina) inside the Nahuel Huapi National Park (Fig. 1). The Llao-Llao and Gutiérrez stream were sampled 2-3 times per month, from August 2012 to January 2013. In Laguna Fantasma, the sampling was performed biweekly during 2010 and 2011. In this site, the sample collection was prolonged during 2012; however, $R$. variegata did not occur during this hydroperiod.

Laguna Fantasma has a well-developed littoral area with vegetation and undergoes huge fluctuations in area and volume along the season, occasionally filled with water all year round. The Llao-Llao marsh is covered with vegetation and usually has prolonged hydroperiods, for two or more years without drying up. Finally, the Gutiérrez backwater area is a permanent pool crossed by the Gutiérrez stream with high fluctuations in its water level.

The dip-netting (hand net $36 \times 25 \mathrm{~cm} ; 50 \mu \mathrm{m}$ mesh) sampling technique was used to collect $R$. variegata larvae and other macroinvertebrates. Sampling was carried out in the vegetated areas during the daytime, because preliminary monitoring (Jara and Perotti, 2010; Jara et al., 2013) showed that most of the invertebrate species tend to concentrate in these areas during the daytime. The number of sweeps was determined according to the area of each pond. Each horizontal net sweeping was done along $2 \mathrm{~m}$ in the littoral zone, integrating the water column. 


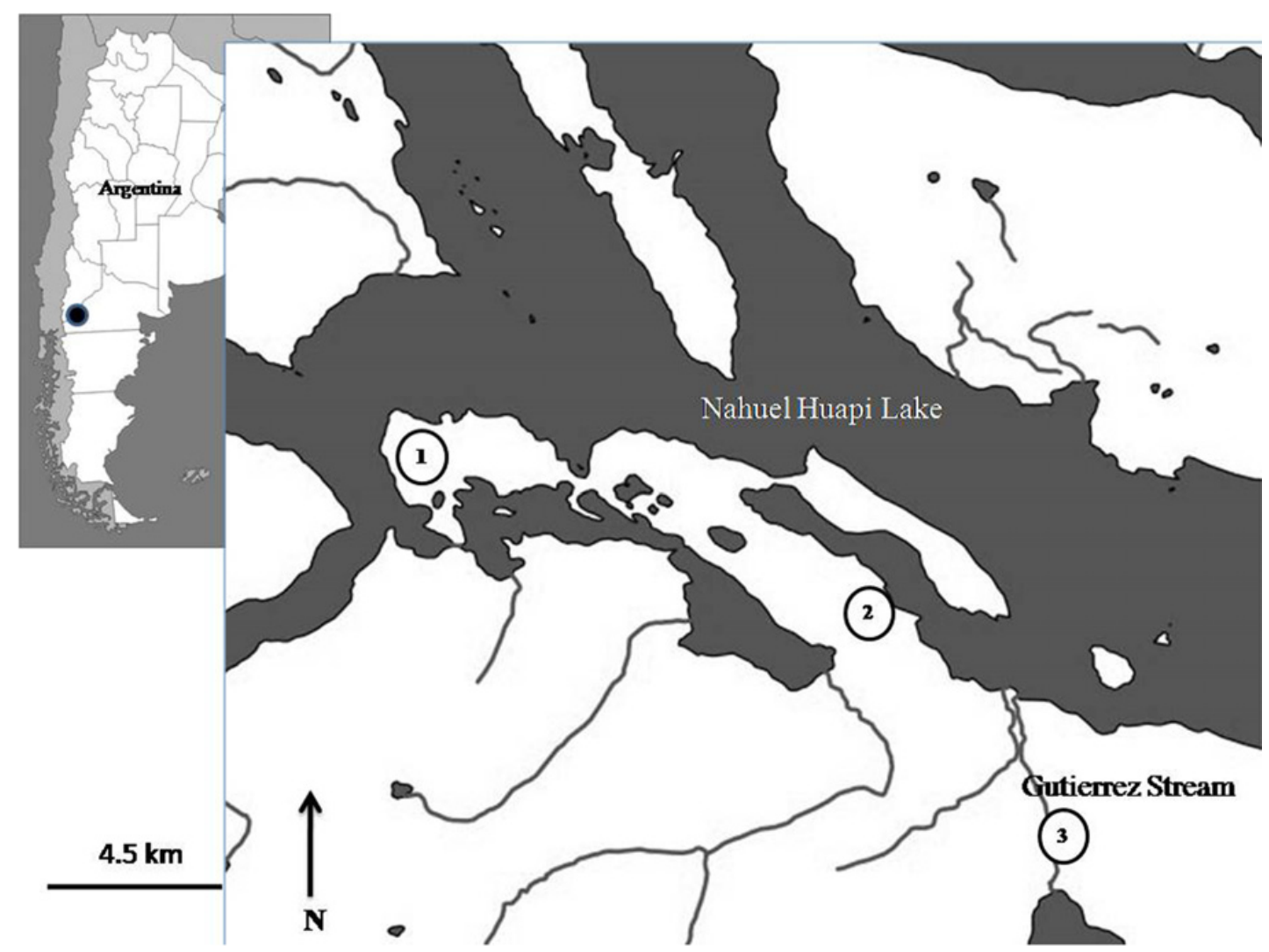

Fig. 1. Map of the study area. The wetlands are located in the western side of San Carlos de Bariloche city, inside the Nahuel Huapi National Park. Numbers refer to wetland location: 1 - Llao-Llao marsh, 2 - Laguna Fantasma and 3 - Gutiérrez backwater stream.

The samples collected were poured into a white plastic tray and examined to estimate the frequency of individuals of the different species, under direct microscope or naked eye, as required. All captured individuals were photographed in the field using a digital camera. These photographs were later used in the laboratory to estimate the body length of each predator, using the free software ImageJ.

\section{Laboratory study}

Three series of laboratory experiments were performed. The first experimental series was designed to evaluate the predation of Rhionaeschna of different body sizes using mosquito larvae (Culex sp.), amphipods (Hyalella patagonica), copepods (Parabroteas sarsi), cladocerans (Daphnia conmutata) and tadpoles (Pleurodema thaul) as prey, separately. The second experimental series aimed to assess predation by conspecifics (cannibalism) of $R$. variegata. The third experimental series was intended to assess the incidence of IGP on the survivorship of Rhionaeschna using the predatory insects Rhantus antarcticus (Coleoptera: Dityscidae), Notonecta vereertbruggheni (Heteroptera: Notonectidae) and Belostoma bifoveolatum (Heteroptera: Belostomatidae). The two latter experiments were performed proving differential availability of alternative prey (with and without alternative prey).
The following general conditions apply to all the experiments. All predatory insects and prey items were collected using a sweep net, from ponds near to the Photobiology Laboratory $\left(41^{\circ} 7^{\prime} 43.53^{\prime \prime} \mathrm{S}, 71^{\circ} 25^{\prime} 12.95^{\prime \prime} \mathrm{W}\right)$. Insects were placed into individual plastic containers $(250 \mathrm{~mL})$ filled with filtered $(50 \mu \mathrm{m})$ pond water and fed ad libitum with an assortment of prey (e.g., mosquito larvae, Daphnia sp.). This setup was maintained for 1-3 days in an environmental chamber, at $18^{\circ} \mathrm{C}$ and under a $12 \mathrm{~h}$ light: $12 \mathrm{~h}$ dark photoperiod (spring conditions). All predators were starved $24 \mathrm{~h}$ prior to feeding trials.

Tadpoles of $P$. thaul (body length \pm 1 SE, $12.7 \pm 0.33 \mathrm{~mm}$ ), the cladoceran Daphnia commutata $(2.20 \pm 0.25 \mathrm{~mm})$, the copepod P. sarsi $(4.87 \pm 0.08 \mathrm{~mm})$, Culex sp. larvae $(5.83 \pm 0.14 \mathrm{~mm})$ and the amphipod $H$. patagonica $(9.01 \pm 0.6 \mathrm{~mm})$ were used as prey. These species are the most common and abundant invertebrates in Patagonian wetlands and although they show seasonal variation in their relative abundances, they co-occur from September to December in the three wetlands studied (Perren, 2008; García, 2010; Jara et al., 2012). The copepod P. sarsi and the cladoceran D. commutata were maintained in $5 \mathrm{~L}$ buckets filled with pond water providing natural prey and the flagellate alga Chlamydomonas reinhardtii from laboratory cultures. Tadpoles of the frog $P$. thaul and amphipods were incubated in $15 \mathrm{~L}$ flat plastic containers, filled with pond water and fed with 
a suspension of the algae Chlamydomonas and Scenedesmus sp.

\section{Experiment 1: effect of $\mathrm{R}$. variegata body size on the survivorship of different prey}

In order to standardize prey biomass, six tadpoles or amphipods, and 12 zooplankters or mosquito larvae were offered to four size classes of $R$. variegata larvae, small $(4.3-5.5 \mathrm{~mm})$, medium $(11.2-13.1 \mathrm{~mm})$, large $(23.7-$ $26.5 \mathrm{~mm})$ and extra-large (34.1-36.2 mm). A total of 100 experimental units were set up: five replicates for each of the five prey species exposed separately to each of the four Rhionaeschna size classes. Each replicate was set up in a $750 \mathrm{~mL}$ plastic bowl filled with filtered pond water. Prey was put into the containers $24 \mathrm{~h}$ previous to the addition of the predators. The trials were set up inside an environmental chamber set at $18^{\circ} \mathrm{C}$; light was supplied by two fluorescent lamps (Phillips daylight, TLT 40W/54RS). A cylindrical wooden rod was placed in each container to serve as a perch for the predator. After incubation of $2 \mathrm{~h}$, the number of prey remaining alive was recorded in each replicate. The exposure period was established following preliminary experiments and corresponding to a reduction of $50 \%$ of the prey.

\section{Experiment 2: cannibalism in $\mathrm{R}$. variegata larvae and the influence of alternative prey}

In this experimental series, the proportion of small larvae preyed by conspecifics of different sizes was measured to estimate the importance of cannibalism in $R$. variegata. Three body size classes of the odonate larvae were used: small $(4.3-5.5 \mathrm{~mm})$, medium $(11.2-13.1 \mathrm{~mm})$ and large $(23.7-26.5 \mathrm{~mm})$. Plastic bowls $(15 \mathrm{~cm}$ diameter $)$ were filled with filtered pond water with a portion of stem $(10 \mathrm{~cm})$ of Myriophyllum quitense and served as experimental containers. Six small- or medium-sized larvae as prey and one medium- or large-sized larvae of Rhionaeschna as predator were added to each of the experimental units (Table 1). Also, to evaluate the effect of alternative prey on cannibalism, a treatment including 12 mosquito larvae (mean size $5.83 \pm 0.14 \mathrm{~mm}$ ) were placed together with six Rhionaeschna prey and one Rhionaeschna predator (medium- or large-sized larvae) (Table 1). After an incubation of $2 \mathrm{~h}$, the number of prey remaining alive was recorded in each experimental unit.

\section{Experiment 3: effect of IGP by predatory insects on $\mathrm{R}$. variegata larvae}

In order to study the effect of potential incidence of IGP on the survivorship of Rhionaeschna larvae, three predatory insects that co-occur with this odonate (Jara et al., 2013) and having different body sizes were selected: $N$. vereertbruggheni (Heteroptera: Notonectidae; instar IV) $(9.1 \pm 0.5 \mathrm{~mm})$, B. bifoveolatum (Heteroptera: Belostomatidae; adult) $(24.54 \pm 0.89 \mathrm{~mm})$ and $R$. antarcticus (Coleoptera: Dityscidae) $(19.9 \pm 1.78 \mathrm{~mm})$.
Table 1. Summary and details of the laboratory experiment (treatments and replicates per treatment) designed to study the IGP on larvae of the odonate $R$. (experiments 2 and 3 ).

\begin{tabular}{|c|c|c|c|}
\hline \multicolumn{4}{|l|}{$\overline{\text { Feeding trials }}$} \\
\hline \multicolumn{4}{|l|}{ Experiment 2: Cannibalism } \\
\hline Predator (Rhionaeschna) & $\begin{array}{c}\text { Rhionaeschna } \\
\text { prey }\end{array}$ & $\begin{array}{l}\text { Culex } \\
\text { prey }\end{array}$ & Replicates \\
\hline$\overline{1 \mathrm{M}}$ & $6 \mathrm{~S}$ & - & 5 \\
\hline $1 \mathrm{~L}$ & $6 \mathrm{~S}$ & - & 5 \\
\hline $1 \mathrm{~L}$ & $6 \mathrm{M}$ & - & 5 \\
\hline $1 \mathrm{M}$ & $6 \mathrm{~S}$ & 12 & 5 \\
\hline $1 \mathrm{~L}$ & $6 \mathrm{~S}$ & 12 & 5 \\
\hline $1 \mathrm{~L}$ & $6 \mathrm{M}$ & 12 & 5 \\
\hline \multicolumn{4}{|c|}{ Experiment 3: Intraguild predation } \\
\hline \multicolumn{4}{|c|}{ Intraguild predator } \\
\hline 1 Notonecta instar IV & $6 \mathrm{~S}$ & - & 5 \\
\hline 1 Notonecta instar IV & $6 \mathrm{M}$ & - & 5 \\
\hline 1 Rhantus & $6 \mathrm{M}$ & - & 5 \\
\hline 1 Rhantus & $6 \mathrm{~S}$ & - & 5 \\
\hline 1 Belostoma adult & $6 \mathrm{~S}$ & - & 5 \\
\hline 1 Belostoma adult & $6 \mathrm{M}$ & - & 5 \\
\hline 1 nymph Notonecta instar IV & $6 \mathrm{~S}$ & 12 & 5 \\
\hline 1 nymph Notonecta instar IV & $6 \mathrm{~S}$ & 12 & 5 \\
\hline 1 Rhantus & $6 \mathrm{M}$ & 12 & 5 \\
\hline 1 Rhantus & $6 \mathrm{~S}$ & 12 & 5 \\
\hline 1 Belostoma adult & $6 \mathrm{~S}$ & 12 & 5 \\
\hline 1 Belostoma adult & $6 \mathrm{M}$ & 12 & 5 \\
\hline
\end{tabular}

L, large Rhionaeschna larvae; M, medium-sized Rhionaeschna larvae and $\mathrm{S}$, small-sized Rhionaeschna larvae.

These predators were collected from the Llao-Llao marsh between December 2012 and January 2013. The experiment was a $3 \times 2 \times 2$ factorial with five replicates summarizing a total of 60 experimental units: three different intraguild predators (Notonecta, Belostoma and Rhantus), two Rhionaeschna body sizes (small and medium larvae) and two levels of alternative prey (with and without mosquito larvae) (Table 1). Six small- or medium-sized larvae as prey and one insect predator of each of the three different species were added to each of the experimental units (Table 1). A treatment including 12 mosquito larvae (mean size $5.83 \pm 0.14 \mathrm{~mm}$ ) placed together with six Rhionaeschna prey and one of each of the three species of predatory insects was set up in order to evaluate the effect of alternative prey on IGP (Table 1). After an incubation of $2 \mathrm{~h}$, the number of prey remaining alive was recorded in each experimental unit.

\section{Statistical analysis}

Body sizes of Rhionaeschna and each of the predatory insects co-occurring in each of the three wetlands (Notonecta, Belostoma, Cyanallagma, Erythrodiplax and Rhantus) were compared by means of $t$-tests. The effect of Rhionaeschna size (small, medium, large and extra-large larvae) on the proportion of survivorship of different prey (Daphnia, Parabroteas, Culex and Hyalella and 


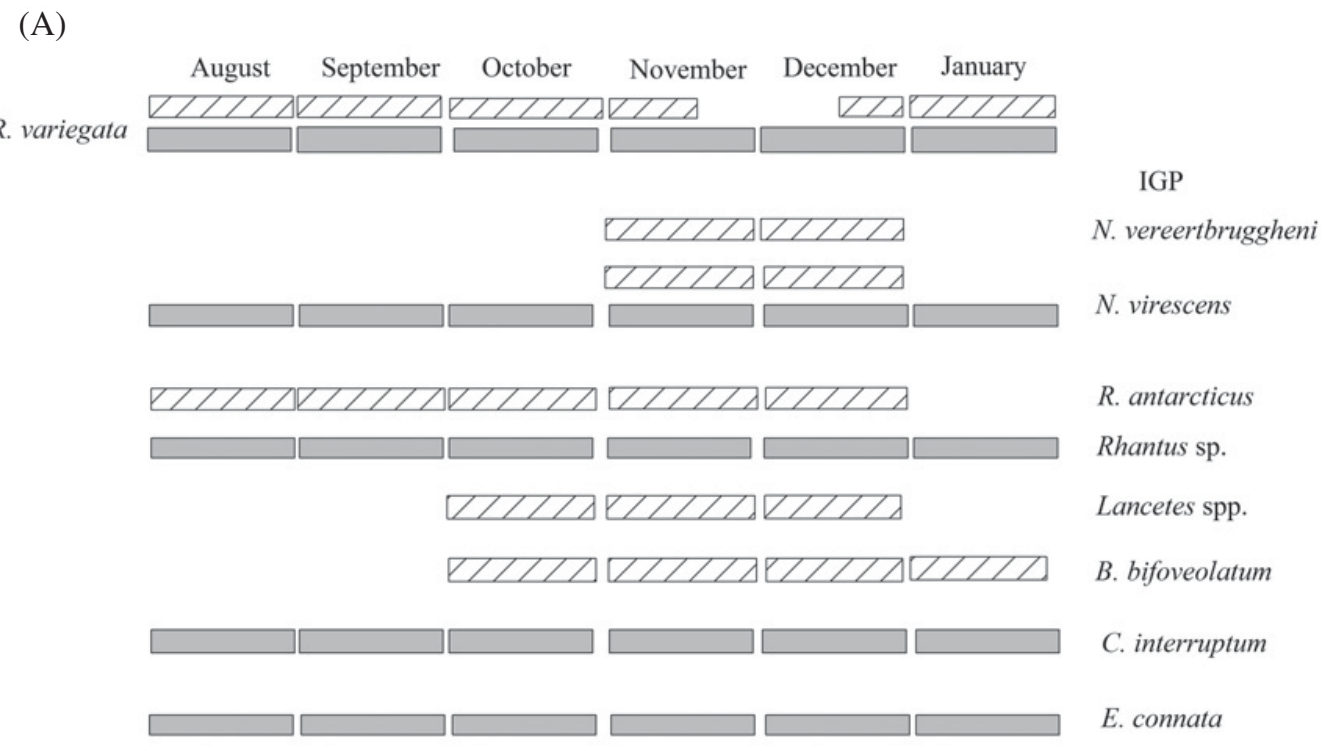

(B)

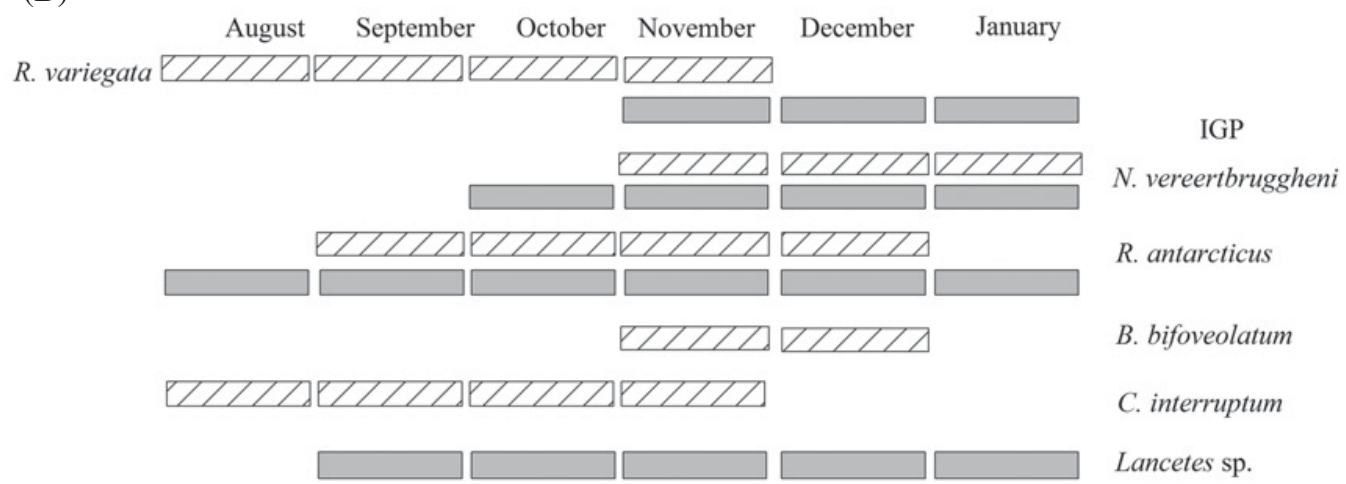

Fig. 2. Phenology of R. variegata and intraguild predators in three wetlands. (A) Hatched bars: Llao-Llao marsh (temporary wetland), gray bars: Gutiérrez stream (permanent wetland) during the hydroperiod 2012; (B) Laguna Fantasma (temporary pond): hatched bars and gray bars represent Rhionaeschna's phenology during the hydroperiods 2010 and 2011, respectively.

Pleurodema tadpoles) (arcsine transformed) was analyzed using a two-way analysis of variance (ANOVA). The results from the cannibalism experiment were analyzed with Mann-Whitney $U$-tests, comparing the proportion of $R$. variegata larvae predated between control (in the presence of mosquito larvae) and treatments (in the absence of mosquito larvae). The results of the experiment for IGP by heterospecific predators on odonate larvae were analyzed with a three-way ANOVA (independent variables: predator species, $R$. variegata body size and presence of alternative prey), followed by Tukey's honest significant difference (HSD) post hoc tests. Analyses were carried out with SigmaStat 9.1.

\section{Results}

\section{Field study}

The body size of $R$. variegata larvae ranged from 3 to $40 \mathrm{~mm}$ in the wetlands surveyed. The emergence of this species began in late October (spring) and continued throughout early summer in the three wetlands; however, the phenology of Rhionaeschna varied among sites (Figs. 2(A) and (B)). In the Llao-Llao marsh, Rhionaeschna showed an older cohort in August (Fig. 2(A)) with comparatively larger individuals than other co-occurring predatory insects (Fig. 3). During September and October, new predators including Belostoma colonized the marsh. At this time, the body size of Belostoma did not differ significantly from that of Rhionaeschna (Fig. 3, t-test $P>0.05$ for all comparisons). During November, an important emergence of Rhionaeschna larvae was detected, thereby setting the starting point of a new reproductive season of the species in the marsh. In early summer, Rhionaeschna larvae were significantly smaller than those of the other co-occurring predators (Fig. 3, $t$-test $P<0.05$ ). This summer cohort of Rhionaeschna failed because the wetland dried up in January 2013. In comparison with this wetland, the Gutiérrez stream showed Rhionaeschna individuals of different cohorts and thus different sizes co-occurring 

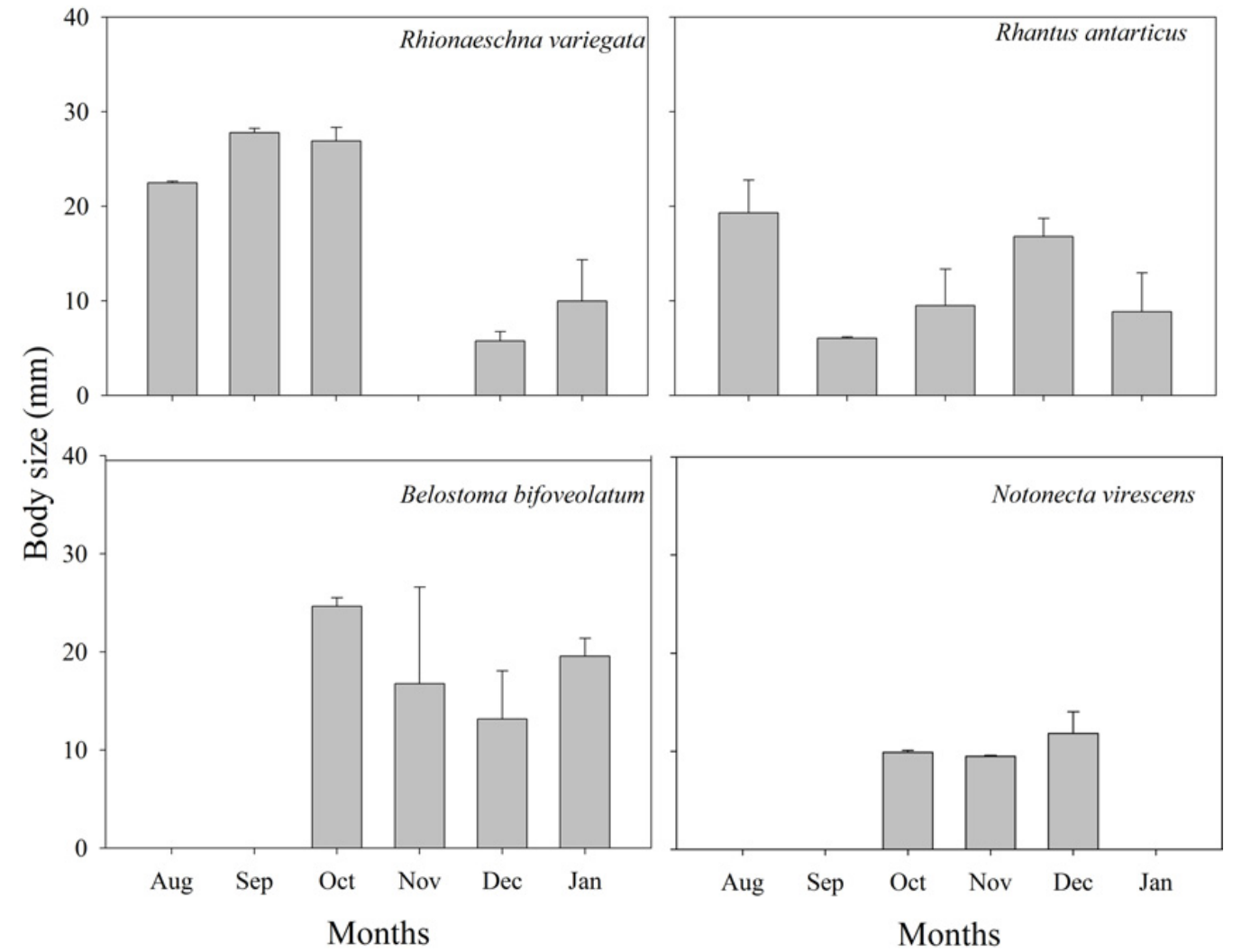

Fig. 3. Body size distribution of $R$. variegata larvae and intraguild predators (mean size \pm SD mm) observed in 2012 in Llao-Llao marsh.

particularly in the littoral vegetation (Fig. 4). In this permanent wetland, the assemblage of predatory insects showed differences in species composition and their phenology. Additionally, all prey species were present year round in the Gutiérrez stream (Figs. 2 and 4), whereas, in the two temporary wetlands, predatory insects colonized seasonally (Fig. 2). In each sampling occasion in Gutierrez stream, the body size of Rhionaeschna differed with that of each accompanying intraguild predators ( $t$-test $<0.05$ in all cases) (Fig. 4).

The phenology of Rhionaeschna in Laguna Fantasma varied between years (Fig. 2(B)). In 2010, the older cohort of $R$. variegata was found in August occurring with Cyanallagma interruptum until November when all larvae emerged. In 2011, a spring cohort of Rhionaeschna developed later, from November to January. Between 2010 and 2011, the composition of the predator assemblage in the pond changed, being $C$. interruptum and B. bifoveolatum recorded only during 2010 (Fig. 2(B)).

\section{Laboratory study}

Experiment 1: effect of $\mathrm{R}$. variegata body size on the survivorship of different prey

The survivorship of all prey species assayed was significantly affected by the presence of $R$. variegata larvae
(Fig. 5). Body size of the Rhionaeschna affected significantly the survivorship of prey $(F=25.16, P<0.001)$. The survivorship to Rhionaeschna predation was significantly different among different prey types and also the interaction between the prey type and Rhionaeschna size resulted significant $(F=1.97, P=0.046)$. In particular, the extralarge Rhionaeschna larvae consumed similarly all the different prey offered in the trials $(F=1.16, P=0.35)$, whereas the large size larvae had a greater impact on the survivorship of Daphnia, Culex sp. and Hyalella compared to its impact on tadpoles of Pleurodema and on the copepod Parabroteas ( $F=16.03, P<0.001$; $t$-test, $P<0.05$ for the comparison between Daphnia, Culex sp. and Hyalella versus the other two species). The medium and small sizes of Rhionaeschna impacted significantly on the survivorship of Daphnia and Culex sp. larvae as compared to the remaining prey species $(F=35.78$, $P<0.001 ; t$-test $P<0.05$ and $F=14.17, P<0.001 ; t$-test $P<0.05$, respectively). Summarizing, large and extralarge Rhionaeschna larvae have a higher effect than the two smaller body sizes $(F=16.78, \quad P<0.001 ; \quad t$-test $P<0.001)$.

\section{Experiment 2: cannibalism in $\mathrm{R}$. variegata larvae and the influence of alternative prey}

The experiment designed to study intraspecific predation showed that large Rhionaeschna larvae consumed 

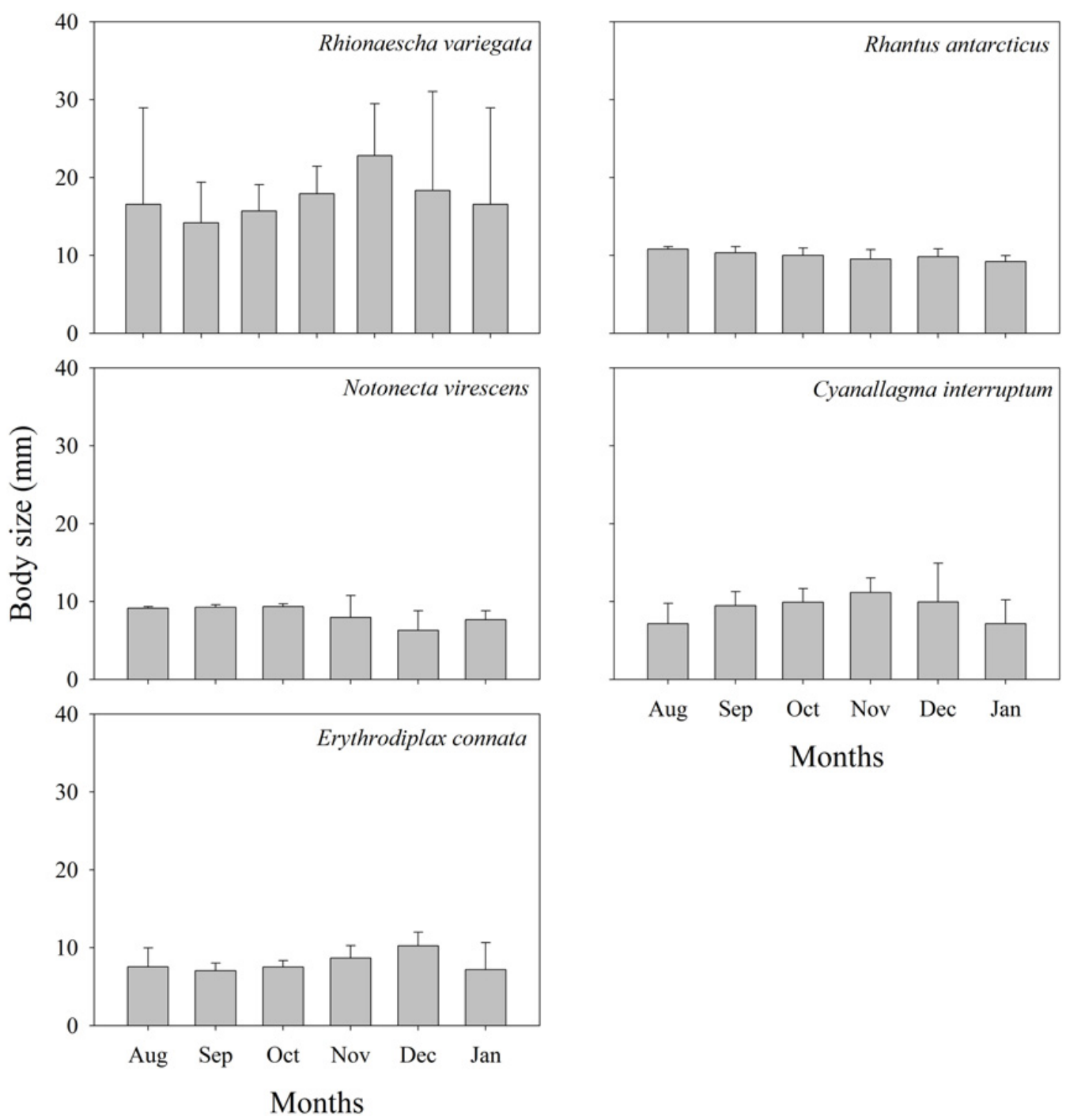

Months

Fig. 4. Body length of $R$. variegata larvae and intraguild predators (mean body size $\pm \mathrm{SD}$, in mm) observed during the hydroperiod 2012 in Gutierrez stream.

similarly small- and medium-sized Rhionaeschna larvae in the treatments with and without alternative prey (Mann-Whitney $U$-test, $P>0.05$ for all three comparisons, Fig. 6). Then, the data from these treatments were pooled and analyzed using one-way ANOVA on ranks. The results obtained evidenced that large larvae of Rhionaeschna consumed smaller than the medium-sized conspecifics $\left(H_{3}=6.84, P=0.03 ; q=3.43, P<0.05\right)$.

\section{Experiment 3: effect of IGP by predatory insects on \\ $\mathrm{R}$. variegata larvae}

A three-way ANOVA was performed to examine the effects of intraguild predators, Rhionaeschna body size, the presence of alternative prey and their interactive effects (Table 2). Both the intraguild predator and the presence of alternative prey influenced the survivorship of Rhionaeschna larvae. Among the intraguild predators analyzed, Belostoma preyed substantially smaller and medium-sized Rhionaeschna larvae than the other two predators, Rhantus and Notonecta $(P<0.05$ for both comparisons; Fig. 7). When Notonecta was used as intraguild predator, the presence of mosquito larvae as alternative prey reduced the consumption of Rhionaeschna larvae $(P<0.05)$. In addition, Notonecta consumed smaller-sized Rhionaeschna larvae than medium-sized ones (Table 2; $P<0.05 ;$ Fig. 7). The effect of the other predatory insects on Rhionaeschna did not differ regardless of the availability of alternative prey $(P>0.05)$.

\section{Discussion}

\section{Phenology of $\boldsymbol{R}$. variegata larvae and intraguild predators}

The seasonal variation in community composition in the three wetlands studied evidenced particular colonization processes by different species. The results obtained here show a wide variation in the co-occurrence 

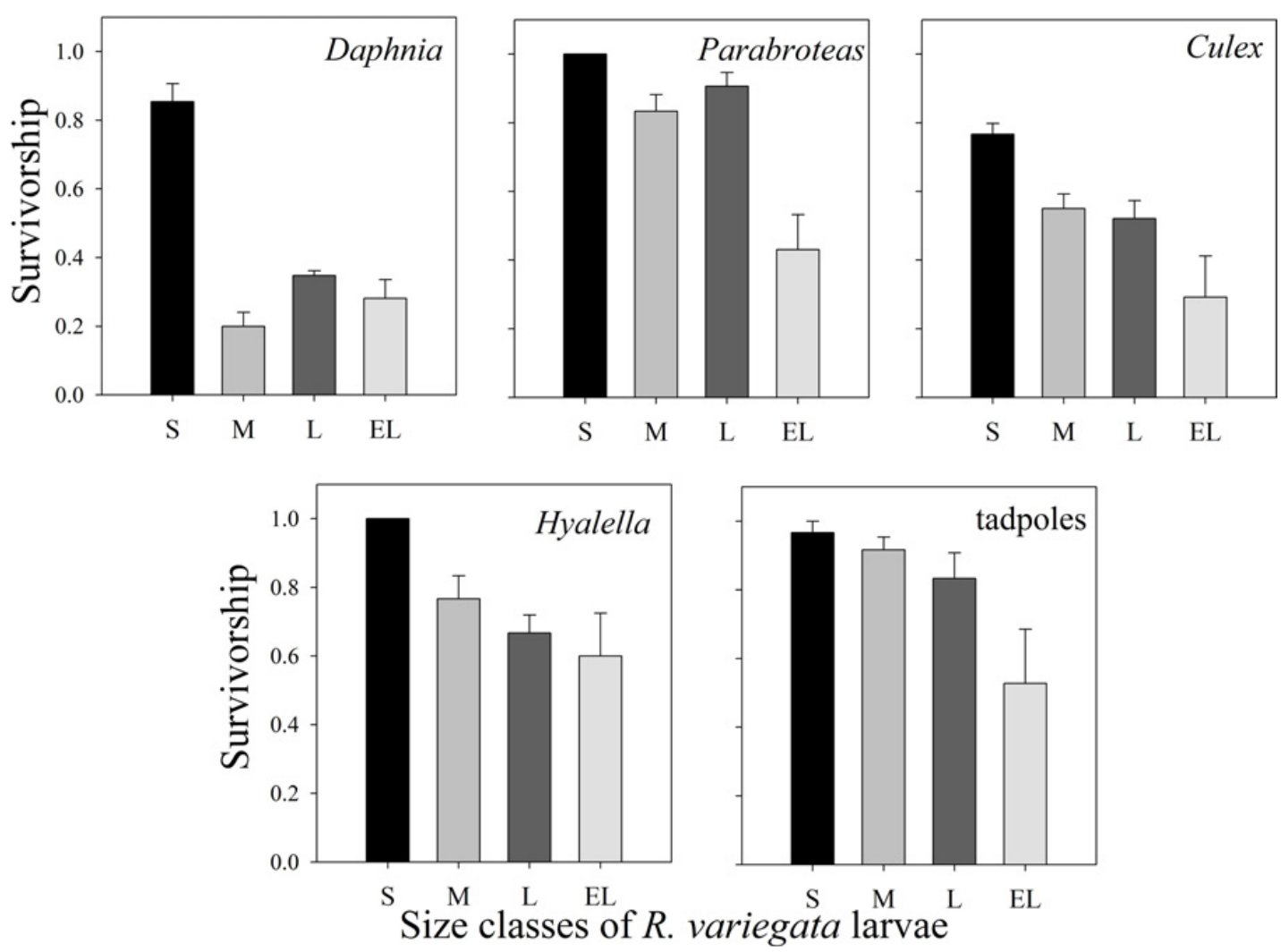

Fig. 5. Survivorship of five prey types (mean $\pm \mathrm{SE}$ ) exposed to four size classes of $R$. variegata. S, small larvae; M, medium larvae; L, large larvae; EL, extra-large larvae.

of nymphs of $R$. variegata and other predatory species. This variation includes the size-specific interactions with different insect predators. The largest predators in the Llao-Llao marsh between August and October 2012 were the overwintering Rhionaeschna larvae. Therefore, in this system cannibalism appears to be prevented by the synchronic development of Rhionaeschna which is reflected by the occurrence of individuals within of a singlesized cohort. In addition, the fact that Rhionaeschna is the largest predatory insect reduces the potential for IGP in the LLao-Llao marsh. Later in the hydroperiod, during December, the development of a new cohort of Rhionaeschna, smaller than co-occurring predators, may likely enhance predation by larger conspecifics as well as by other predatory insects in this system.

The phenology of Rhionaeschna and its predators varied spatially (i.e., among wetlands) and also inter annually within the same wetland, as observed particularly in Laguna Fantasma. Consequently, the magnitude of cannibalism and IGP by other insects may show significant inter annual variation. Variation in the timing of exposure to predation, such as observed in Rhionaeschna, may be common in natural successions (Alford, 1989). Yet, its potential effects have been poorly analyzed in competition and predation studies. The population of Rhionaeschna from the Gutiérrez stream may be subjected to more even predation risk along the year, whereas the populations of the Llao-Llao marsh and Laguna
Fantasma may be exposed to fluctuating predation risks along the hydroperiod.

\section{Predation by $\boldsymbol{R}$. variegata on prey community and the effect of body size on the survival of prey}

The effect of $R$. variegata on the survival of different co-occurring prey is size-dependent, as revealed by the feeding experiments in which larger Rhionaeschna consumed up to three times more prey than the smallest. Developmental changes in morphological features of Rhionaeschna larvae related to prey detection and capture, such as the size and shape of the mask and the head width, may explain the greater predation rates shown by larger larvae of Rhionaeschna (Westfall and May, 1996; Burks et al., 2001).

Odonates occupy an intermediate position in benthic food webs, being both predator and prey (Johnson et al., 1995). Rhionaeschna larvae can be found at different depths perching on vegetation in areas where both pelagic and benthic prey may be available. Preys used in the present experiments can be found in both pelagic and benthic habitats. Tadpoles and amphipods are more frequent in the benthic compartment while zooplankton species and mosquito larvae dwell in the water column. Although benthic predators such as dragonflies are considered to have a major impact on benthic organisms, some authors 
Table 2. Results of the three-way ANOVA performed to study the main and interactiveeffects of intraguild predators (Notonecta, Belostoma and Rhantus), alternative prey (mosquito larvae) on the survivorship of small- and medium-sized larvae of $R$. variegata.

\begin{tabular}{|c|c|c|c|}
\hline Factors & d.f. & $F$ & $P$ \\
\hline Intraguild predator & 2 & 60.903 & $<0.001$ \\
\hline Prey size & 1 & 0.735 & 0.396 \\
\hline Alternative prey & 1 & 4.971 & 0.03 \\
\hline Intraguild predator $\times$ prey size & 2 & 3.912 & 0.027 \\
\hline Intraguild predator $\times$ alternative prey & 2 & 1.441 & 0.247 \\
\hline Prey size $\times$ alternative prey & 1 & 0.265 & 0.609 \\
\hline Intraguild predator $\times$ Prey size $\times$ alternative prey & 2 & 2.206 & 0.121 \\
\hline
\end{tabular}

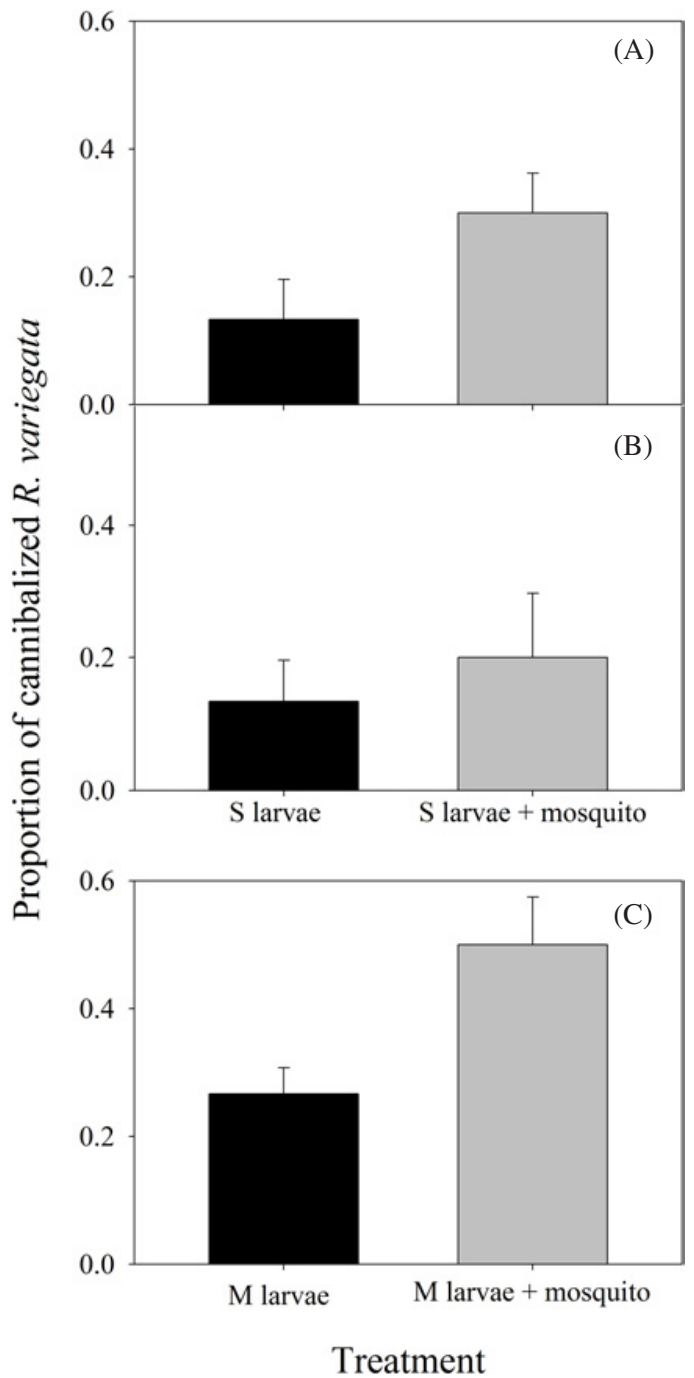

Fig. 6. Proportion of $R$. variegata larvae (mean $\pm \mathrm{SE}$ ) cannibalized by large and medium size conspecifics in the presence and absence of mosquito larvae as alternative prey. (A) Large Rhionaeschna as predator of small conespecifics with and without alternative prey; (B) medium size Rhionaeschna as predator of small conespecifics with and without alternative prey and (C) large Rhionaeschna as predator of medium size conespecifics with and without alternative prey.

have shown that odonate larvae can have a considerable impact on the survivorship of pelagic prey such as cladocerans (i.e., Burks et al., 2001). Here, Rhionaeschna

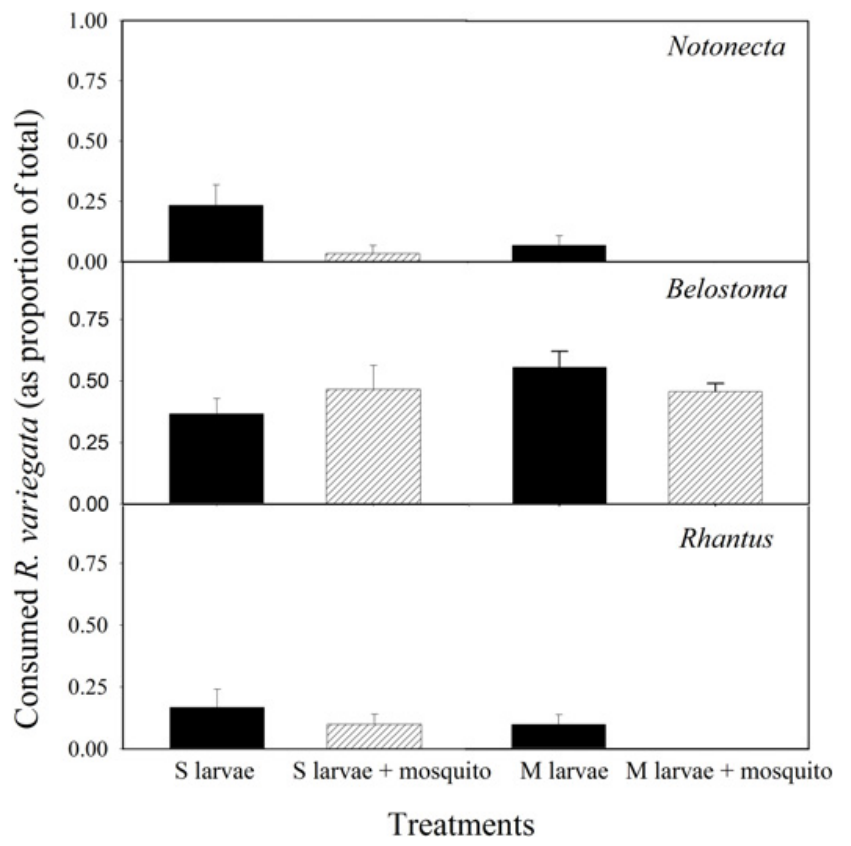

Fig. 7. Proportion of small (S) and medium (M) size classes of $R$. variegata (mean $\pm 1 \mathrm{SE}$ ) preyed in treatments with and without mosquito larvae as alternative prey when incubated separately with three intraguild predatory species.

larvae were found to exert a major impact on small pelagic species. Contrastingly, larger benthic prey, such as tadpoles and amphipods, were consumed at a lesser extent which may alternatively imply that they pose a greater capture and manipulation effort for the predator and/or alternatively that they provide faster satiation. In fact, when large Rhionaeschna larvae fed to satiation were incubated with prey, no capture attempts were observed.

The extra-large larvae of Rhionaeschna preyed heavily on all prey species offered. The medium and large sizes of Rhionaeschna preyed mainly upon mosquito larvae and cladocerans, and secondarily copepods and tadpoles. Copepods are faster swimmers than cladocerans and also are comparatively more evasive. Tadpoles are the largest prey items found in local ponds and they have been observed to react rapidly to Rhionaeschna presence, reducing abruptly their activity (Jara and Perotti, 2010). Some authors have found that dragonflies had little effect on zooplankton assemblages, but a major effect on mosquito larvae and tadpoles (van Buskirk, 1988; 
Fincke et al., 1997; Stav et al., 1999). We suspect that in the wetlands studied other predatory insects such as notonectids may have a higher impact on zooplankton than dragonflies (Jara et al., 2012).

As it has been observed by other authors, the strength of the predator-prey interaction in aquatic insects is sizedependent (Bo et al., 2007; McCoy et al., 2011; Klecka et al., 2013). In this study, medium- and large-sized Rhionaeschna consumed a larger proportion of the prey offered as compared to small larvae. As most odonate species, Rhionaeschna larvae can swallow a wide range of prey sizes, even organisms larger than themselves. They can consume their prey either in discrete portions or as a whole by manipulating them with the mandibles. Small size odonate larvae usually consume small prey because they have difficulties handling and capturing larger prey (Henrikson, 1990).

\section{Cannibalism rate and differences in body size}

Cannibalism, which appears as an important source of mortality for $R$. variegata larvae in the laboratory experiment, may exert some pressure on the population dynamics by shaping the size structure in natural environments were different size cohorts co-occur. Although in my laboratory experiments, the prey density was different among alternative prey treatments, the rate of cannibalism on small $R$. variegata larvae measured was remarkably similar. Nevertheless, future experimental work should take into account the effect of prey density on the rate of cannibalism in $R$. variegata and other dragonfly species.

van Buskirk (1989) reported that populations of dragonflies that inhabit fishless temporary ponds are probably regulated by cannibalism. Although cannibalism depends on larval density, only small larvae are likely to suffer the highest predation levels by larger conspecifics (van Buskirk, 1989, 1993). Recently, Crumrine (2010) found that cannibalism in the larvae of Anax imperator depends on the temperature regime and suggested that cannibalism may be most common when water temperatures are warm. In this study, predation of the $R$. variegata larvae by large conspecifics could be important at sites and times with high densities of co-occurring size cohorts, as may be the case of permanent wetlands such as the Gutiérrez stream. The effects of temperature on cannibalism of Patagonian dragonflies are not known. However, the temperature in the studied wetlands varies widely along the season, with stable and freezing temperatures in autumn and fluctuating warmer temperatures in late spring and summer. It is worth mentioning that during spring and summer large differences between day and night temperatures are usual in all wetlands, particularly in the shallower, lentic ones. Thus, if the pattern observed by Crumrine (2010) could be applied to the $R$. variegata larvae, it may be plausible to propose that cannibalism occurs more frequently during late spring and summer. Even though odonate larvae are general predators, and that cannibalism in this group is opportunistic, intraspecific predation would tend to overall reduce intraspecific competition and size differences in the population.

\section{IGP and body size of interacting species}

When $R$. variegata and mosquito larvae were offered together to intraguild predators, the mortality of $R$. variegata was similar. This suggests that the presence of alternative prey did not influence the strength of IGP, at least under the laboratory conditions applied. In natural habitats, the incidence of IGP could be determined by factors other than prey availability. In a previous study documenting interference effects among dragonfly larvae, Crowley et al. (1987) found that the presence of large Tetragoneuria reduced the movement and capture rate of the smaller conspecifics. Other studies describing interference effects in odonates have focused on damselflies and their behavioral response to the presence of dragonflies or fish (Heads, 1985, 1986). In this study, interference may occur, perhaps by the presence of large $R$. variegata and other intraguild predators influence the behavior of small odonate larvae. Decreased movement is the most common response in odonate larvae, although this does not always have a demonstrable cost in terms of feeding rates (Chowdhury and Corbet, 1988; Anholt, 1990; McPeek, 1990a, 1990b; Johansson, 1991a, 1991b).

The experimental results showed that the sizes of the intraguild predators are directly related to the risk imposed on Rhionaeschna. For example, small odonate larvae experienced higher mortality due to large sympatric predatory insects such as Belostoma. Notonecta and Rhantus larvae are smaller predators that have little effect on the survival of small- and medium-sized Rhionaeschna larvae. Belostoma are been usually observed in very shallow areas $(<10 \mathrm{~cm})$ with high concentration of organic matter. Belostomatids are considered sit-and-wait predators, associated with emergent vegetation (Babbitt and Jordan, 1996). Individuals of B. bifoveolatum were captured in shallow places of the wetlands studied, at a depth between 5 and $30 \mathrm{~cm}$. Rhionaeschna larvae are more abundant in deeper parts of the wetland (40-90 cm of depth) associated with rushes, and alternating quiet perching periods with active periods dwelling on the vegetation or in the bottom. This differential habitat use could reduce the encounter between Belostoma and small Rhionaeschna larvae and therefore its predatory impact. Nevertheless, further studies are needed to confirm this inference.

The wide variation in size along the ontogeny of $R$. variegata, the phenology patterns observed in the field and the experimental results indicate that this predator may shift its position in the trophic food web. Large dragonfly larvae impact on different prey species, including invertebrates and vertebrates. In contrast, small larvae experience different levels of cannibalism by large conspecifics and IGP by co-occurring predatory insects. Both, cannibalism and IGP are size-dependent and appear to be regulated by different mechanisms such as the timing and 
particular phenology of prey and predator. These two factors are closely associated to the hydroperiod; permanent habitats allow establishment of several cohorts of larvae differing in age and size. In this condition, the smaller individuals may experience cannibalism by larger conspecifics. Additionally, permanent wetlands can be colonized by many different predatory species that may consume small odonate larvae. Wetlands undergoing a dry season may allow the synchronic development of $R$. variegata larvae. In such population structure, slight differences in size among individuals and lower to negligible impact cannibalism can be expected.

Acknowledgements. This investigation was performed under the institutional animal care guidelines established by the Bureau of National Parks of Argentina (APN). Subsecretaria de Medio Ambiente of San Carlos de Bariloche authorized the samplings in Laguna Fantasma and Parque Municipal Llao-Llao. M. Diéguez, Haro G. and Gonzalez Eusevi M.V. corrected the English style. This work was founded by UNComa B166 and by a research grant PICT 2011 (Agencia, FONCyT) to F. Jara.

\section{References}

Alford R.A., 1989. Variation in predator phenology affects predator performance and prey community composition. Ecology, 70, 206-219.

Anholt B.R., 1990. An experimental separation of interference and exploitative competition in a larval damselfly. Ecology, $71,1483-1493$.

Arim M. and Marquet P.A., 2004. Intraguild predation: a widespread interaction related to species biology. Ecol. Lett., 7, 557-564.

Babbitt K. and Jordan F., 1996. Predation on Bufo terrestris tadpoles: effects of cover and predator identity. Copeia, 1996, 485-488.

Benke A.C., 1978. Interactions among coexisting predators: a field experiment with dragonfly larvae. J. Anim. Ecol., 47, 335-350.

Benke A.C. and Benke S.S., 1975. Comparative dynamics and life histories of coexisting dragonfly populations. Ecology, 56, 302-317.

Bo T., Fenoglio S. and Malacarne G., 2007. Diet of Dinocras cephalotes and Perla marginata (Plecoptera: Perlidae) in an Apenine stream (northwestern Italy). Can. Entomol., 139, 358-364.

Bo T., Fenoglio S., López-Rodríguez M.J. and Tierno de Figueroa J.M., 2011. Trophic behaviour of the dragonfly Cordulegaster boltoni (Insecta: Odonata) in small creeks in NW Italy. Entomol. Fennica, 22, 255-261.

Burks R.L., Jeppesen E. and Lodge D.M., 2001. Pelagic prey and benthic predators: impacts of odonate predation on Daphnia. J. N. Amer. Benthol. Soc., 20, 615-628.

Chowdhury S.H., Corbet P.S., 1988. Feeding rate of larvae of Enallagma cyathigerum (Charpentier) in the presence of conspecifics and predators (Zygoptera: Coenagrionidae). Odonatologica, 17, 115-119.
Cohen J.E., Pimm S.L., Yodzis P. and Saldana J., 1993. Body sizes of animal predators and animal prey in food webs. J. Anim. Ecol., 62, 67-78.

Corbet P.S., 1999. Dragonflies: Behavior and Ecology of Odonata, Cornell University Press, Ithaca, New York, 830 p.

Crowley P.H., Dillon P.M., Johnson D.M. and Watson C.N., 1987. Intraspecific interference among larvae in a semivoltine dragonfly population. Oecologia, 71, 447-456.

Crumrine P., 2010. Body size, temperature, and seasonal differences in size structure influence the occurrence of cannibalism in larvae of the migratory dragonfly, Anax junius. Aquat. Ecol., 44, 761-770.

Fincke O.P., Ynoviak S.P. and Hanschu R.D., 1997. Predation by odonates depresses mosquito abundance in water-filled tree holes in Panama. Oecologia, 112, 244-253.

García R.D., 2010. Ciclo de vida del copépodo depredador Parabroteas sarsi (Calanoida, Centropagidae): Impacto del canibalismo en la población de la Laguna Fantasma. Licenciatura thesis, Universidad Nacional del Comahue, San Carlos de Bariloche.

Hasse M.P., 1978. The Dynamics of Arthropod Predation, Princeton University Press, Princeton, 248 p.

Heads P.A., 1985. The effect of invertebrate and vertebrate predators on the foraging movements of Ischnura elegans larvae (Odonata: Zygoptera). Freshw. Biol., 15, 559-571.

Heads P.A., 1986. The costs of reduced feeding due to predator avoidance: potential effects on growth and fitness in Ischnura elegans larvae (Odonata, Zygoptera). Ecol. Entomol., 11, 369-373.

Henrikson B.I., 1990. Predation on amphibian eggs and tadpoles by common predators in acidified lakes. Holarct. Ecol., 13, 201-206.

Heyer W.R., McDiarmid R.W. and Weigmann D.L., 1975. Tadpoles, predation and pond habitats in the tropics. Biotropica, 7, 100-111.

Holt R.D. and Huxel G.R., 2007. Alternative prey and the dynamics of intraguild predation: theoretical perspectives. Ecology, 88, 2706-2712.

Ilmonen J. and Suhonen J., 2006. Intraguild predation, cannibalism, and microhabitat use in Calopteryx virgo and Somatochlora metallica larvae: a laboratory experiment. Aquat. Ecol., 40, 59-68.

Jara F.G., 2008. Tadpole-odonate larvae interactions: influence of body size and diel rhythm. Aquat. Ecol., 42, 503-509.

Jara F.G. and Perotti M.G., 2006. Variacion ontogenetica en la palatabilidad de los renacuajos de Bufo spinulosus papillosus Philippi, 1902 (Anura, Bufonidae). Cuad. Herpetol., 19, 37-42.

Jara F.G. and Perotti M.G., 2009. Toad tadpole responses to predator risk: ontogenetic change between constitutive and inducible defenses. J. Herpetol., 43, 82-88.

Jara F.G. and Perotti M.G., 2010. Risk of predation and behavioral response in three anuran species: influence of tadpole size and predator type. Hydrobiologia, 644, 313-324.

Jara F.G., Perotti M.G. and Diéguez M.C., 2012. Distribution of backswimmers in shallow ponds of Patagonia and their predatory role on a common tadpole-copepod assemblage. N.Z. J. Mar. Freshw. Res., 46, 459-473.

Jara F.G., Úbeda C.A. and Perotti M.G., 2013. Predatory insects in lentic freshwater habitats from northwest Patagonia: richness and phenology. J. Nat. Hist., 47, 2749-2768. 
Johansson A., 1991a. Caddis larvae cases (Trichoptera, Limnephilidae) as anti-predatory devices against brown trout and sculpin. Hydrobiologia, 211, 185-194.

Johansson F., 1991b. Foraging modes in an assemblage of odonate larvae-effects of prey and interference. Hydrobiologia, 209, 79-87.

Johansson F., 1993. Effects of prey type, prey density and predator presence on behaviour and predation risk in a larval damselfly. Oikos, 68, 481-489.

Johansson F. and Crowley P.H., 2008. Larval cannibalism and population dynamics of dragonflies. In: Lancaster J. and Briers R.A. (eds.), Aquatic Insects: Challenges to Populations, CABI, Wallingford, 36-54.

Johnson D.M., Martin T.H., Mahato M., Crowder L.B. and Crowley P.H., 1995. Predation, density dependence, and life histories of dragonflies: a field experiment in a freshwater community. J. N. Am. Benthol. Soc., 14, 547-562.

Klecka J., Boukal D.S. and Rasmussen J., 2013. Foraging and vulnerability traits modify predator-prey body mass allometry: freshwater macroinvertebrates as a case study. J. Anim. Ecol., 82, 1031-1041.

McCoy M.W., Bolker B.M., Warkentin K.M. and Vonesh J.R., 2011. Predicting predation through prey ontogeny using size-dependent functional response models. Amer. Nat., 177, 752-766.

McPeek M.A., 1990a. Determination of species composition in the Enallagma damselfly assemblages of permanent lakes. Ecology, 71, 83-98.

McPeek M.A., 1990b. Behavioral differences between Enallagma species (Odonata) influencing differential vulnerability to predators. Ecology, 71, 1714-1726.

Memmott J., Martinez N.D. and Cohen J.E., 2000. Predators, parasitoids and pathogens: species richness, trophic generality and body sizes in a natural food web. J. Anim. Ecol., 69, $1-15$.

Merrill R.J. and Johnson D.M., 1984. Dietary niche overlap and mutual predation among coexisting larval anisoptera. Odonatologica, 13, 387-406.

Muzón J., 1995. Los Odonata de la Patagonia Argentina. Rev. Soc. Entomol. Argent., 54, 1-14.

Muzón J., 1997. Odonata from Patagonia: species richness and distributional patterns. Biogeographica, 73, 123-133.

Muzón J., 2009. Current knowledge of Patagonian Odonata. Rev. Soc. Entomol. Argent., 68, 163-167.

Muzón J. and Von Ellenrieder N., 1999. Status and distribution of Odonata (Insecta) within natural protected areas in Argentina. Biogeographica, 75, 119-128.

Perotti M.G., Diéguez M.C. and Jara F.G., 2005. Estado del conocimiento de humedales del norte patagónico (Argentina): aspectos relevantes e importancia para la conservación de la biodiversidad regional. Rev. Chil. Hist. Nat., 78, 723-737.

Perren G., 2008. El banco de resistencia de cladóceros de lagunas temporarias del norte patagónico: estructura y patrones de abundancia y distribución. Licenciatura thesis, Universidad Nacional del Comahue, San Carlos de Bariloche.
Pimm S.L., 1978. On feeding on more than one trophic level. Nature, 275, 542-544.

Polis G.A., Meyers C.A. and Holt R.D., 1989. The ecology and evolution of intraguild predation: potential competitors that eat each other. Annu. Rev. Ecol. Syst., 20, 297-330.

Simberloff D. and Dayan T., 1991. The guild concept and the structure of ecological communities. Annu. Rev. Ecol. Syst., 22, 115-143.

Stav G.L., Blaustein A. and Margalith J., 1999. Experimental evidence for predation risk sensitive oviposition by a mosquito, Culiseta longiareolata. Ecol. Entomol., 24, 202-207.

Suutari E., Rantala M.J., Salmela J. and Suhonen J., 2004. Intraguild predation and interference competition in the endangered dragonfly Aeshna viridis. Oecologia, 140, 135-139.

Urban M.C., 2007. Predator size and phenology shape prey survival in temporary ponds. Oecologia, 154, 571-580.

van Buskirk J., 1988. Interactive effects of dragonfly predation in experimental pond communities. Ecology, 69, 857-867.

van Buskirk J., 1989. Density-dependent cannibalism in larval dragonflies. Ecology, 70, 1442-1449.

van Buskirk J., 1992. Competition, cannibalism, and size class dominance in a dragonfly. Oikos, 65, 455-464.

van Buskirk J., 1993. Population consequences of larval crowding in the dragonfly Aeshna juncea. Ecology, 74, 1950-1958.

von Ellenrieder N., 2001. Species composition and distribution patterns of the Argentine Aeshnidae (Odonata: Anisoptera). Rev. Soc. Entomol. Argent., 60, 39-60.

Vonesh J.R., 2003. Density- and trait-mediated effects of predators across life history stages. PhD thesis, University of Florida, Gainesville, FL.

Warren P.H. and Lawton J.H., 1987. Invertebrate predator-prey body size relationships: an explanation for upper triangular food webs and patterns in food web structure? Oecologia, 74, 231-235.

Westfall M.J. and May M.L., 1996. Damselflies of North America, Scientific Publishers, Gainesville, Florida, 649 p.

Wilbur H.M., 1984. Complex life cycles and community organization in amphibians. In: Price P.W., Slobodchikoff C.W. and Goud W.S. (eds.), A New Ecology: Novel Approaches to Interactive Systems, John Wiley \& Sons, New York, NY, 195-224.

Wissinger S.A., 1989. Seasonal variation in the intensity of competition and predation among dragonfly larvae. Ecology, 70, 1017-1027.

Wissinger S.A., 1992. Niche overlap and the potential for competition and intraguild predation between size-structured populations. Ecology, 73, 1431-1444.

Wissinger S.A. and McGrady J., 1993. Intraguild predation and competition between larval dragonflies: direct and indirect effects on shared prey. Ecology, 74, 207-218.

Wissinger S.A., Sparks G.B., Rouse G.L., Brown W.S. and Steltzer H., 1996. Intraguild predation and cannibalism among larvae of detritivorous caddisflies in subalpine wetlands. Ecology, 77, 2421-2430. 